\title{
Investigation on Damping Characteristics of Hydrostatic Bearing Film by Using Scale Method
}

Sheng-Yen Hu ( $\nabla$ shengyenhu@cycu.edu.tw)

Chung Yuan Christian University

Wen-Chou Chen

Chung Yuan Christian University

Chien-Hsun Wang

Chung Yuan Christian University

Hsin-Ming Fu

Chung Yuan Christian University

Yuan Kang

Chung Yuan Christian University

\section{Research Article}

Keywords: Hydrostatic bearing, Single-degree-of-freedom, Static stiffness, Dynamic response, Damping ratio scale

Posted Date: December 9th, 2021

DOI: https://doi.org/10.21203/rs.3.rs-1126942/v1

License: (c) (i) This work is licensed under a Creative Commons Attribution 4.0 International License.

Read Full License 


\title{
Investigation on Damping Characteristics of Hydrostatic Bearing Film by Using Scale Method
}

\author{
Sheng-Yen $\mathrm{Hu}^{*}$ \\ Wen-Chou Chen \\ Chien-Hsun Wang \\ Hsin-Ming $\mathrm{Fu}$ \\ Yuan Kang
}

Department of Mechanical Engineering

Chung Yuan Christian University

* Full postal address

Ph.D. Sheng-Yen Hu

Department of Mechanical Engineering

Chung Yuan Christian University

Chung-Li 320, Taiwan, R.O.C.

Tel.: +886-3-2654334

Fax: +886-3-2654399

E-mail address: shengyenhu@cycu.edu.tw 


\begin{abstract}
The resonant peaks can be suppressed by damping, those effects is dependent on damping ratio of system. In this paper, we propose a scaling method to evaluate the damping ratio of hydrostatic bearings for the data from model test. This method fits specifically for the overdamping of all hydrostatic bearing. This is direct and the easiest method to obtain the damping characteristics of oil film for the lowest band before the first resonant peak. The frequency responses of acceleration per force for a single-degree-of-freedom mass-spring-damper model is used to generate the evaluation scales for the damping ratios of the modal test results of worktable mounting on hydrostatic bearing. The case study for experimental results of the impact response are evaluated for damping ratio of the hydrostatic film by these method. Furthermore, using this scaling method, the influences of three types of compensations on the damping ratio of a hydrostatic bearing are compared. The results reveal that the constant flow has the largest damping ratio, and the capillary restrictor has the smallest one.
\end{abstract}

Keywords: Hydrostatic bearing, Single-degree-of-freedom, Static stiffness, Dynamic response, Damping ratio scale. 


\section{Nomenclature}

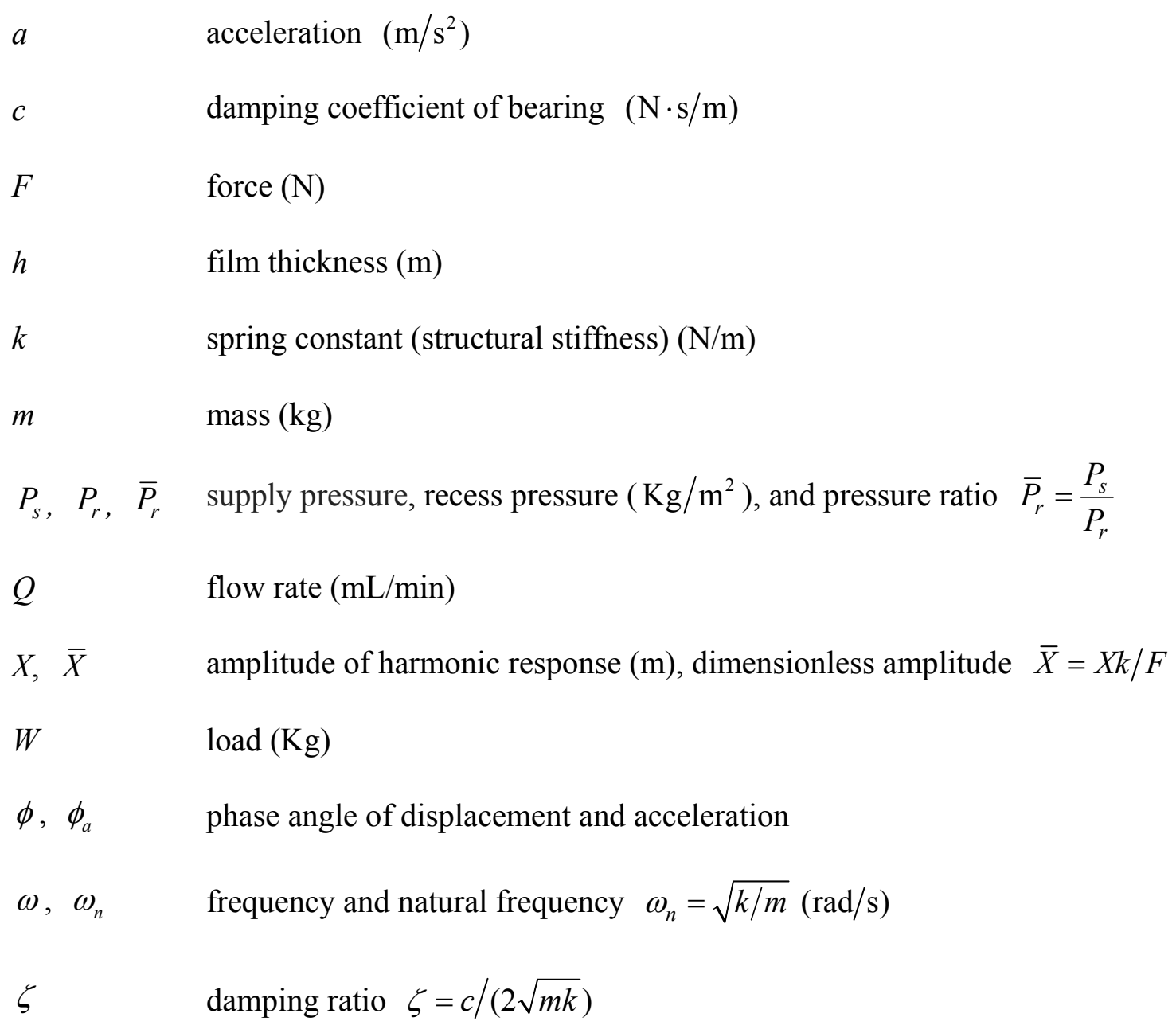

\section{INTRODUCTION}

Brown [1] used an equivalent spring-damper system to analyze the dynamic behavior of a hydrostatic thrust bearing and experimentally investigated its validity. He reported that hydrostatic thrust bearings have high stiffness and high damping, which make them very suitable for machine tool applications. Rohde and Ezzat [2] studied the relationship between the excitation frequency and the dynamic coefficient. They reported that the oil film stiffness decreases with an increase in the excitation frequency and the damping increases relatively. Ghosh et al. [3][4] used fluid compressibility, fluid inertia, and eccentricity as the conditional parameters to explore the relationship between the dynamic coefficient of the oil film and the excitation frequency of the squeezed oil film. The results showed that stiffness decreases and 
damping increases as fluid compressibility and inertia increase. Kang et al. [5] simulated the dynamic responses of the worktable mounting on a closed-type hydrostatic bearing. They although revealed that an appropriately designed hydrostatic bearing exhibits overdamping and traditional methods, such as the logarithmic attenuation method, the half-power bandwidth method, and the transient response, cannot be utilized to obtain overdamped behavior. Kang et al. [6] used experimental methods to explore the influence of capillary restriction parameters, supply pressure, oil film thickness, and other parameters on the static and dynamic characteristics of open hydrostatic slides, and compare theoretical analysis with experimental results to establish the design method of hydrostatic slides. However, no damping coefficient or damping ratio was determined by their study.

Structural modal test methods are divided into single-degree-of-freedom (SDOF) and multiple-degree-of-freedom methods, which pass the resonance peaks to determine the natural frequency and the damping ratio through a curve. Ewins [7] and Heylen et al. [8] explored structural modal testing methods but did not discuss overdamping. Solva's handbook [9] states that methods to measure the damping coefficient are classified into time-domain approaches and frequency-domain approaches. The former obtain responses step by step from the excitation with a single frequency, and the latter obtain responses from random steps that sweep the harmonic or impact excitation and extract the modal parameters from the determinations of the modal model by the methods mentioned above.

Tiwari et al. [10] studied the experimental identification of bearing parameters extensively by using methods including mathematical modeling, experimental measurement techniques, and parameter extraction algorithms. Zhang et al. [11] identified the linearized oil-film coefficients by fitting the measured frequency response functions to the theoretically calculated ones. Their method can reduce the influence of the phase measurement errors on the estimated results. Jolly et al. [12] studied the characteristics of a hydrostatic journal bearing for an aerospace turbopump. The angle of the oil injection hole and the shape and size of the internal groove were determined using numerical analysis. At the same time, the flow rate of the sliding bearing was measured, and experiments verified the correctness of the theory. Mao [13] proposed an innovative point-to-point contact step excitation method to measure the transient response of hydrostatic bearings. Meanwhile, the experimental results showed that the damping coefficient of the 
ascending stage is less than that of the descending stage. Rowe [14] presented a method for determining the bearing oil film stiffness and damping coefficient from frequency spectrum of experimental data. He proposed the formula to calculate the damping coefficient, which used one frequency to obtain one damping coefficient. His method obtain both coefficients for the individual frequency.

Kang et al. [15] established a scale method of damping ratio and obtained the frequency range of below $300 \mathrm{~Hz}$ for the overdamping scale measurement was sufficient. It is a graph comparison method of damping ratio, which is obtained the entire frequency domain below the 1 st mode by one comparison. The damping ratio we obtained is covering the whole range of frequencies. In this study, the frequency response of acceleration per force for a single-degree-of-freedom mass-spring-damper model is used to generate the scales for damping ratio. Since the damping of hydrostatic film is overdamping, it's damping ratio can be evaluate throughout this range within the range of the frequency below the first mode of the lowest frequency at a type.

\section{CONSTRUCTION OF DAMPING RATIO SCALE FROM ACCELERATION MEASUREMENT}

The spectrum response of the actual hydrostatic bearing support worktable used this scale to identify the damping ratio of an oil film, and then, the mass of the worktable and the resonant frequency were converted into the damping coefficient. The equation of motion for the viscous damping of the SDOF mass-spring system is

$$
m \ddot{x}+c \dot{x}+k x=F \sin (\omega t)
$$

where $m$ is the mass, $c$ is the damping, $k$ is the stiffness of the spring, $x$ is the displacement, and $F \sin (\omega t)$ is the simple harmonic force. Substituting the frequency response $x=X \sin (\omega t-\phi)$ into the motion equation provides the dimensionless amplitude and the phase versus frequency ratio as follows:

$$
\bar{X}=\frac{X k}{F}\left\{\left[1-\left(\frac{\omega}{\omega_{n}}\right)^{2}\right]^{2}+\left[2 \zeta\left(\frac{\omega}{\omega_{n}}\right)^{2}\right]^{2}\right\}^{\frac{-1}{2}}
$$




$$
\phi=\tan ^{-1}\left[\frac{2 \zeta\left(\omega / \omega_{n}\right)}{1-\left(\omega / \omega_{n}\right)^{2}}\right]
$$

where $\zeta=\frac{c}{2 \sqrt{m k}}$ is the damping ratio and $\omega_{n}=\sqrt{k / m}$ is the natural frequency. For a typical single degree-of-freedom mass, the relationship between the dimensionless amplitude and the phase angle versus the frequency ratio can be obtained using Eq. (2), as shown in Fig. 1.

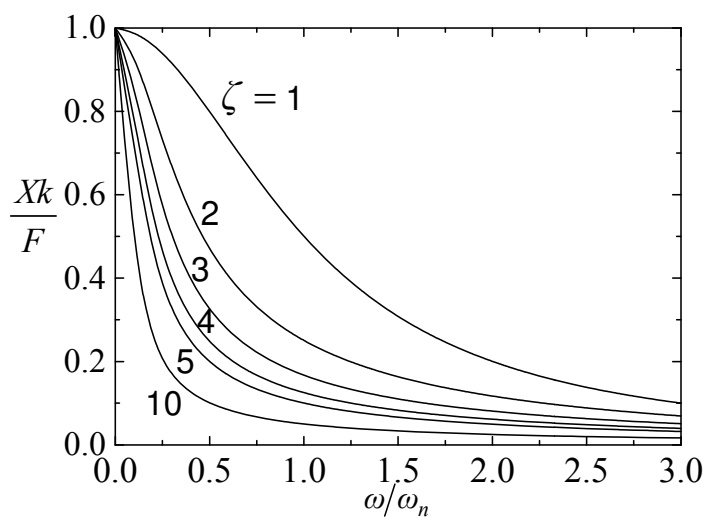

(a)

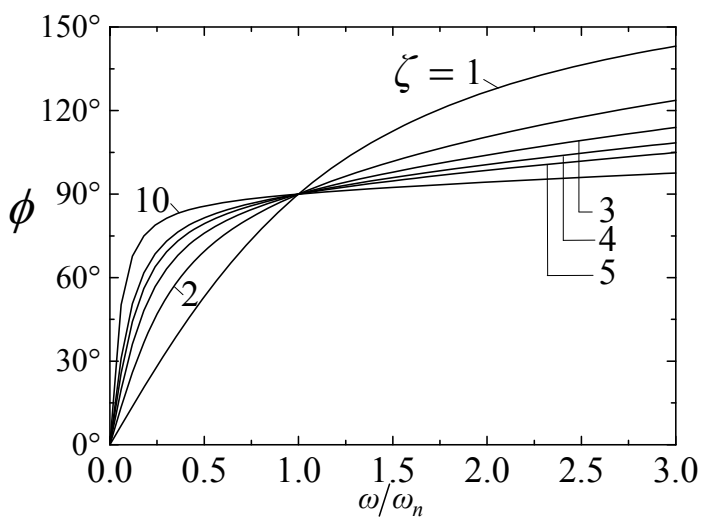

(b)

Fig. 1 The scale of damping ratio in frequency responses of the single degree-of-freedom mass-spring-damper model (a) displacement ratio $X k / F_{0}$ and (b) phase angle $\phi$ versus frequency ratio $\omega / \omega_{n}$.

The actual measured spectrum response between the first resonance peak and the zero frequency is the fundamental frequency mode region. The dimensionless amplitude and the phase angle of the region simulation are used as the scale to determine the damping ratio. Then, the damping factor is calculated using $c=2 \zeta \sqrt{m k}$, where the static stiffness $k$ of the oil film can be obtained by measuring the worktable displacement due to the static load.

The measurement with the accelerometer in the spectrum response experiment is the most convenient, and the obtained frequency response of acceleration per force excitation is the most common. Therefore, the dimensionless amplitude corresponding frequency ratio and the vibration displacement phase angle should be converted into the frequency response of acceleration per force excitation and the phase angle of acceleration, respectively, as follows: 


$$
\begin{aligned}
& \frac{a}{F}=\frac{X}{F} \omega^{2}=\frac{\bar{X}}{k} \omega^{2} \\
& \phi_{a}=\pi-\phi
\end{aligned}
$$

We use experiments to get $k$ and $\omega_{n}$ to transform the displacement ratio and phase angle of displacement relative to excitation force versus frequency ratio into the acceleration per excitation force and the phase angle of acceleration versus frequency by using Eq. (3). For example, an experimental model having oil film stiffness $k=4.22 \times 10^{7} \mathrm{~N} / \mathrm{m}$ and natural frequency $\omega_{n}=646.50 \mathrm{~Hz}$ can be transformed to give the damping ratio scales for the modal testing of this model as shown by Fig. 2 .

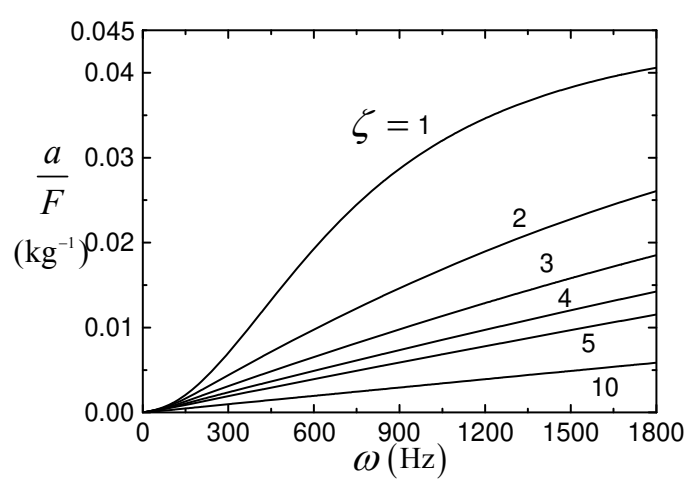

(a) acceleration per force $a / F$

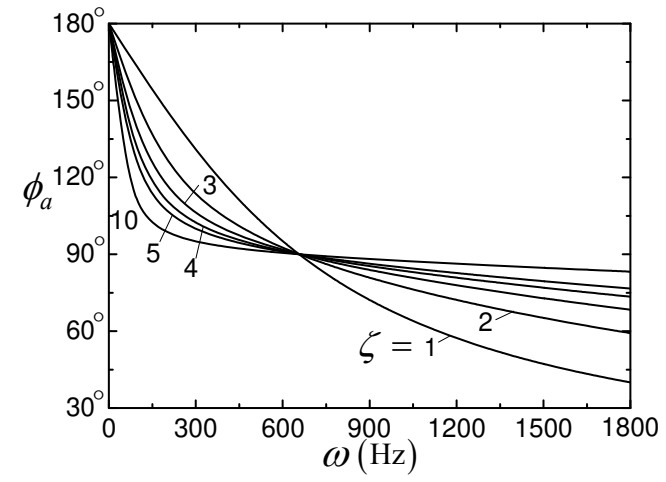

(b) phase angle of acceleration $\phi_{a}$

Fig. 2 The acceleration per force excitation and phase angle of acceleration versus frequency $\omega$.

\section{A PRACTICAL RIG OF HYDROSTATIC BEARING AND ITS WORKTABLE}

The experimental equipment uses constant flow as shown in Fig. 3(a), and uses the restrictors for pressure compensation of hydrostatic bearing as shown in Fig. 3(b). The pump supplies the pressurized oil into the bearing oil recess to form the oil film which supports the worktable and resisted the load changing. The high pressurized oil flowed out from the clearance between the worktable and the bearing sill to the oil tank. One type restrictors of capillary and membrane-type is used to compensate recess pressures. Fig. 3(c) shows the bearing system of an open-type worktable. We used the circular pads, whose diameters were $76 \mathrm{~mm}$ (pad) and $20 \mathrm{~mm}$ (recess). Fig. 3(d) shows the sensors. 


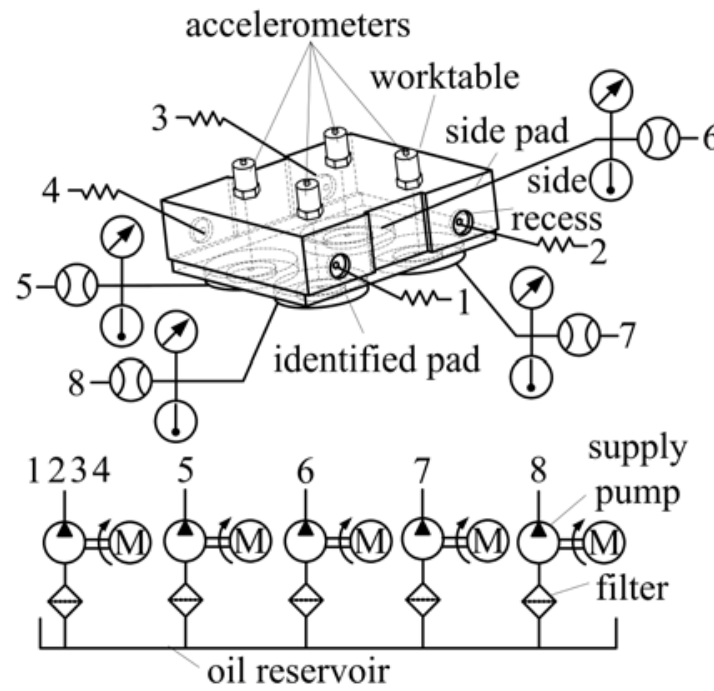

(a) Constant flow

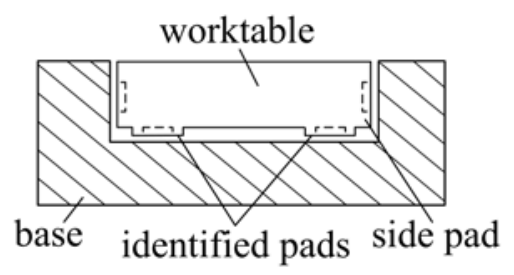

(c) cross-section of open-type worktable

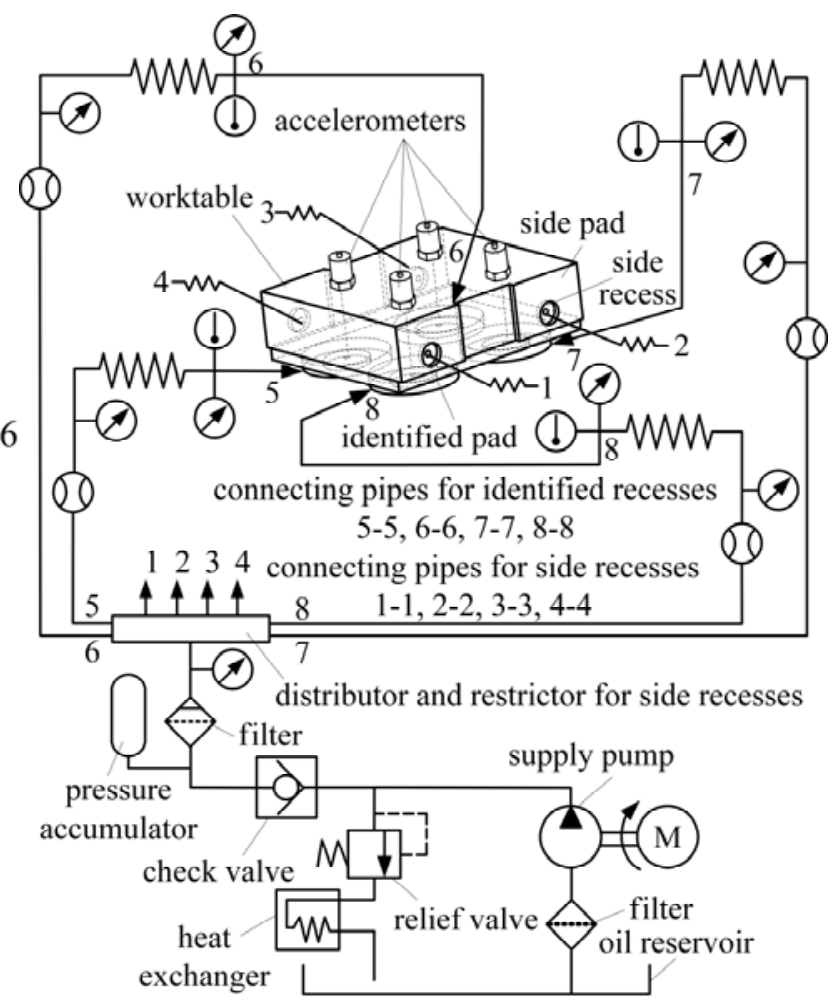

(b) Restrictor(capillary or membrane-type)

$$
\begin{aligned}
& \text { WW- : restrictor } \\
& \text { (1) : thermalmeter } \\
& \text { (b) : flow meter } \\
& \text { ( : pressure sensor }
\end{aligned}
$$

(d) sensor symbols

Fig. 3 Experimental equipment

\subsection{STATIC STIFFNESS OF HYDROSTATIC FILM BY USING RESTRICTORS}

The constant flow realized by a variable-capacity pump controlled by a constant flow valve that gives constant flow for recess pressure varying to bear the load fluctuating. The capillary and membrane-type restrictors is shown in Fig. 4. 


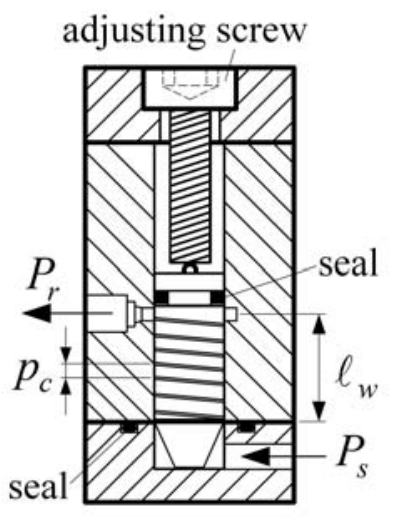

(a) capillary restrictor(in longest status) metal membrane

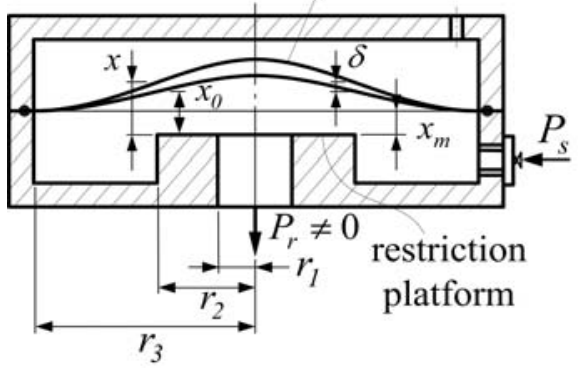

(b) membrane-type restrictor

Fig. 4 The mechanism of the restrictor

The flow through a capillary to a recess can be determined by

$$
Q_{c}=\pi d_{c}^{4}\left(P_{s}-P_{r}\right) / 128 \mu \ell_{c}
$$

where $d_{c}$ is the diameter of the capillary restriction screw, and the length of capillary $\ell_{c}$ is

$$
\ell_{c}=\pi d_{m} n_{w}=\pi d_{m} \frac{\ell_{w}}{p_{c}}
$$

where $d_{m}$ is the mean diameter, $\ell_{w}$ is the working length, $n_{w}$ is the number of working turns, and $p_{c}$ is the screw pitch.

Externally pressurized fluid is fed in and passes through the clearance between membrane and platform surfaces, which is restricted to recess pressure $P_{r}$ and leaves the restrictor to bearing recess. The membrane-type restrictor is subjected to pressure on the one side form $P_{s}$ to $P_{r}$ in radial distribution and the constant pressure of $P_{r}$ on a circular area within the inner radius of restriction platform. The flow rate of the membrane-type restrictor can be described by

$$
Q_{m}=\frac{\kappa_{m}}{\mu}\left(1+\zeta P_{r}\right)^{3}\left(P_{s}-P_{r}\right)
$$

where $\kappa_{m}=\left(\pi \alpha x_{0}\right)^{3}\left(6 \ln r_{2} r_{1}^{-1}\right)^{-1}$ (unit: $\left.\mathrm{m}^{3}\right)$ is restriction parameter of membrane-type restrictor, $\mu$ (unit: $\mathrm{N} \cdot \mathrm{s} / \mathrm{m}^{2}$ ) is dynamic viscosity coefficient, $r_{l}$ is the inner radius of the restriction platform and outlet connecting to the recess, $r_{2}$ is the outer radius of the restriction platform, $\zeta=C_{m} x_{0}^{-1}$ (unit: $\mathrm{m}^{2} / \mathrm{N}$ ), $C_{m}$ (unit: $\mathrm{m}^{3} / \mathrm{N}$ ) is membrane deformation coefficient and which is the deformation due to unit pressure, and $\alpha=$ opening geometric coefficient for flow rate passing through the opening $x_{0}$, which is dependent on deformed shape of membrane due to only supply pressure without recess pressure. Both parameters $\kappa_{m}$ and $\zeta$ can be obtained by identification from experiments or determine design parameters, which can see reference [16]. Using the same parameter identification method, we get the dimensionless deformation coefficient of membrane $\bar{C}_{m}=2.687$. The flow rate of restrictor equal to one of bearing film

$$
Q_{b}=P_{r} h^{3} \gamma / 12 \mu
$$


where $h=h_{0}-e$ is thickness of oil film and $\gamma$ is the restriction parameter of bearing pad, $e$ is worktable displacement. Differentiating flow continuity equation with respect to $e$ gives:

$$
\begin{aligned}
& K=\frac{d W}{d e}=A_{e f f} \frac{d P_{r}}{d e}=3 W \gamma^{\frac{1}{3}} \bar{P}_{r}^{\frac{4}{3}}=3 W \gamma^{\frac{1}{3}} k_{p} \quad \text { for constant flow } \\
& K=3 W \gamma^{\frac{1}{3}}\left(\bar{P}_{r}^{-1}-1\right)^{\frac{2}{3}} \bar{P}_{r}^{2}=3 W \gamma^{\frac{1}{3}} k_{p} \quad \text { for capillary } \\
& K=3 W\left(\frac{\gamma}{12 \kappa_{m}}\right)^{\frac{1}{3}} \frac{\bar{P}_{r}^{\frac{4}{3}}\left(1-\bar{P}_{r}\right)^{\frac{2}{3}}}{1-2 \bar{C}_{m} \bar{P}_{r}+3 \bar{C}_{m} \bar{P}_{r}^{2}}=3 W\left(\frac{\gamma}{12 \kappa_{m}}\right)^{\frac{1}{3}} k_{p} \quad \text { for membrane-type }
\end{aligned}
$$

where $A_{\text {eff }}$ is the effective area, $\bar{C}_{m}=C_{m} P_{s} x_{0}^{-1}$ is dimensionless deformation coefficient of membrane, $k_{p}$ is dimensionless stiffness parameter of hydrostatic bearing, $\bar{P}_{r}=P_{r} / P_{s}$ is pressure ratio, and $W=P_{r} A_{\text {eff }}$ is carried by load hydrostatic pad. Fig. 5 is the simulation result of dimensionless stiffness for three types of compensations by using Eq. (7). It shows the specific design conditions can get the best stiffness for membrane-type and capillary restrictors. The stiffness of constant flow is increasing with pressure ratio increasing.

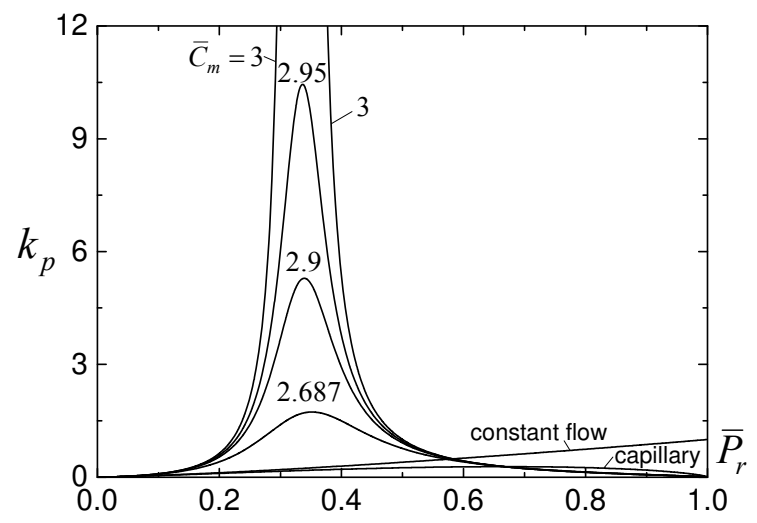

(a) $k_{p}=0 \sim 12$

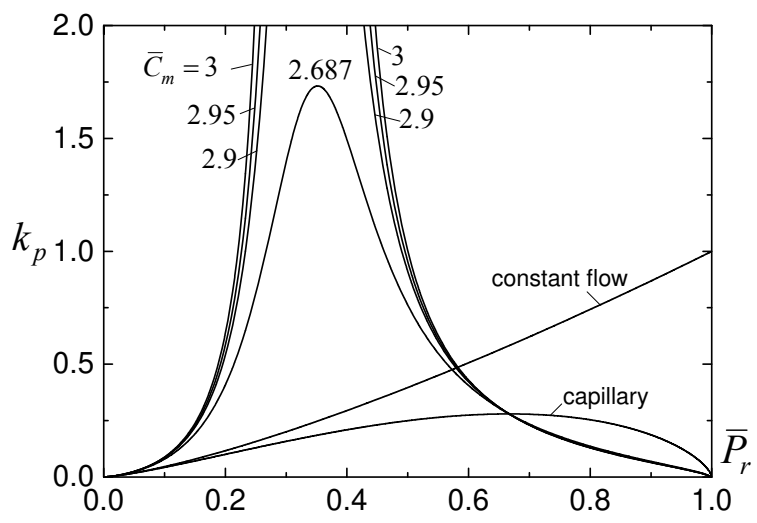

(b) $k_{p}=0 \sim 2$

Fig. 5 dimensionless stiffness of hydrostatic bearing with three types of compensations

\section{EXPERIMENTAL RESULTS AND ESTIMATION}

The measurement range and sensitivity of the pressure meters are $0-50$ bar and 0.15682 $\mathrm{V}(\mathrm{Kg} / \mathrm{cm})$, respectively. The measurement range and sensitivity of the flow meters are $1 \mathrm{~L} / \mathrm{h}-100$ $\mathrm{L} / \mathrm{h}$ and $0.006253 \mathrm{~V}(\mathrm{~cm} / \mathrm{min})$, respectively. IC-type temperature sensors used with an AD590J amplifier, which had the measurement range and sensitivity of $-55-150^{\circ} \mathrm{C}$ and $1 \mu \mathrm{A} / \mathrm{K}$, respectively. The measurement range and sensitivity of the displacement sensors are $\pm 0.2 \mathrm{~mm}$ and less than $2 \mathrm{mV}$, respectively. The measurement range and sensitivity of the accelerometers are $50 \pm \mathrm{g}$ and $99.7 \mathrm{mV} / \mathrm{g}$, respectively. The experiment parameters of pressure compensations are set as follows: $\ell_{w}=20 \mathrm{~mm}, d_{m}=0.4 \mathrm{~mm}, p_{c}=2 \mathrm{~mm}, r_{1}=2 \mathrm{~mm}, r_{2}=4.2 \mathrm{~mm}, r_{3}=5.4 \mathrm{~mm}$, $x_{m}=0.05 \mathrm{~mm}$ and $t_{m}=0.3 \mathrm{~mm}$. In order to control the flow rate and the oil supply pressure, the pressure, flow rate, oil recess working pressure, and the working oil average temperature of the 
bearing oil recess were measured by the sensor. We adjusted the supply pressure or the flow to the appropriate oil film thickness and horizontal position, and measured the displacement of the worktable to calculate the static stiffness of the oil film by changing the load weight of the worktable. The dynamic load was excited by the impact hammer, and the dynamic response was measured by the accelerometer.

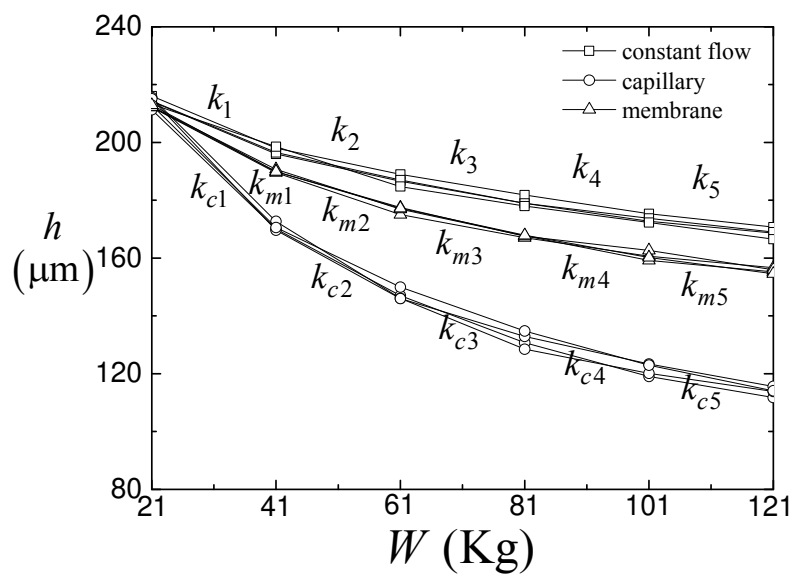

(a)case 1

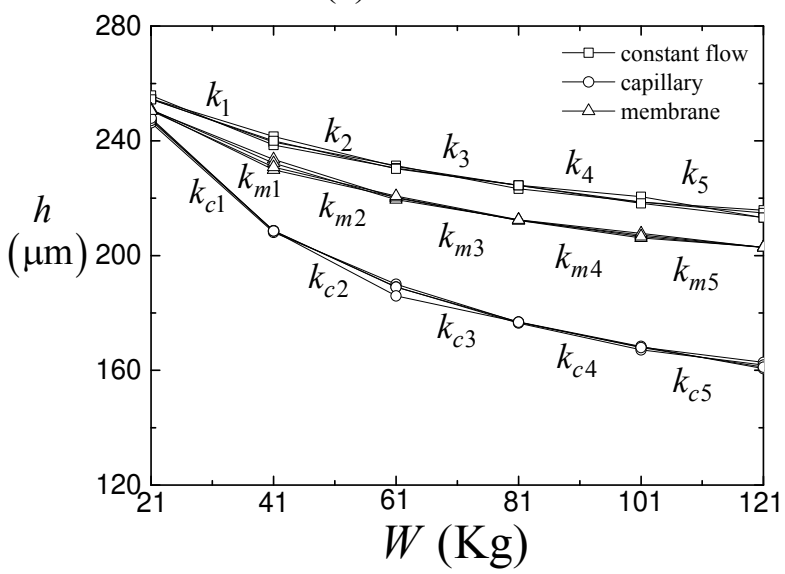

(a)case 2

Fig. 6 The relationship between the loading and displacement of the worktable for three types of compensations by different supply pressure or flow rate

The experimental equipment included a worktable with a weight of $W_{0}=21 \mathrm{Kg}$ supported by the hydrostatic bearing. This worktable weight was increased step by step by adding a mass of $m=20 \mathrm{Kg}$ per step. Then, we measured the displacement of the worktable as shown in Fig. 6 . For Fig. 6, the case 1 and case 2 are $Q=480$ and $800 \mathrm{~mL} / \mathrm{min}$ for constant flow, respectively and $P_{s}=8 \times 10^{4}$ and $12 \times 10^{4} \mathrm{Kg} / \mathrm{m}^{2}$ for capillary and membrane-type, respectively. In the linearization process, $k$ in the interval from $W_{i}$ to $W_{i+1}$ is set as 


$$
k_{i, i+1}=\frac{W_{i+1}-W_{i}}{h_{i}-h_{i+1}}
$$

$k_{i, i+1}$ of the symbol dot for the specific $W$ is determined by the average of two linearized stiffness of its adjacent load ranges is

$$
k_{i}=\frac{k_{i-1, i}+k_{i, i+1}}{2}
$$

The determination results of the static stiffness $k$ and the natural frequency $\omega_{n}$ are summarized into Table 1 for three types of compensations of the experimental rig.

Table 1 Oil film stiffness $k \times 10^{7}(\mathrm{~N} / \mathrm{m})$ and resonance frequency $\omega_{n}(\mathrm{~Hz})$ as load $\Delta W=20$

\begin{tabular}{|c|c|c|c|c|c|}
\hline \multicolumn{6}{|c|}{ constant flow } \\
\hline \multirow{4}{*}{$Q=480 \frac{\mathrm{mL}}{\min }$} & $k_{1}$ & $k_{2}$ & $k_{3}$ & $k_{4}$ & $k_{5}$ \\
\hline & 1.17 & 1.96 & 2.71 & 3.43 & 4.22 \\
\hline & $\omega_{n 1}$ & $\omega_{n 2}$ & $\omega_{n 3}$ & $\omega_{n 4}$ & $\omega_{n 5}$ \\
\hline & 747.39 & 692.24 & 667.10 & 650.28 & 646.50 \\
\hline \multirow{4}{*}{$Q=800 \frac{\mathrm{mL}}{\min }$} & $k_{1}$ & $k_{2}$ & $k_{3}$ & $k_{4}$ & $k_{5}$ \\
\hline & 1.35 & 2.22 & 3.08 & 3.99 & 4.83 \\
\hline & $\omega_{n 1}$ & $\omega_{n 2}$ & $\omega_{n 3}$ & $\omega_{n 4}$ & $\omega_{n 5}$ \\
\hline & 801.29 & 736.13 & 710.74 & 701.52 & 691.51 \\
\hline \multicolumn{6}{|c|}{ membrane-type restriction } \\
\hline \multirow{4}{*}{$P_{s}=8 \times 10^{4} \frac{\mathrm{Kg}}{\mathrm{m}^{2}}$} & $k_{m 1}$ & $k_{m 2}$ & $k_{m 3}$ & $k_{m 4}$ & $k_{m 5}$ \\
\hline & 0.89 & 1.50 & 2.20 & 3.05 & 4.13 \\
\hline & $\omega_{n 1}$ & $\omega_{n 2}$ & $\omega_{n 3}$ & $\omega_{n 4}$ & $\omega_{n 5}$ \\
\hline & 651.78 & 605.69 & 600.40 & 613.53 & 639.80 \\
\hline \multirow{4}{*}{$P_{s}=12 \times 10^{4} \frac{\mathrm{Kg}}{\mathrm{m}^{2}}$} & $k_{m 1}$ & $k_{m 2}$ & $k_{m 3}$ & $k_{m 4}$ & $k_{m 5}$ \\
\hline & 1.05 & 1.78 & 2.57 & 3.72 & 5.06 \\
\hline & $\omega_{n 1}$ & $\omega_{n 2}$ & $\omega_{n 3}$ & $\omega_{n 4}$ & $\omega_{n 5}$ \\
\hline & 708.38 & 658.84 & 649.54 & 677.29 & 707.86 \\
\hline \multicolumn{6}{|c|}{ capillary restriction } \\
\hline \multirow{4}{*}{$P_{s}=8 \times 10^{4} \frac{\mathrm{Kg}}{\mathrm{m}^{2}}$} & $k_{c 1}$ & $k_{c 2}$ & $k_{c 3}$ & $k_{c 4}$ & $k_{c 5}$ \\
\hline & 0.47 & 0.86 & 1.30 & 1.97 & 2.69 \\
\hline & $\omega_{n 1}$ & $\omega_{n 2}$ & $\omega_{n 3}$ & $\omega_{n 4}$ & $\omega_{n 5}$ \\
\hline & 471.08 & 457.61 & 462.21 & 493.60 & 516.51 \\
\hline \multirow{4}{*}{$P_{s}=12 \times 10^{4} \frac{\mathrm{Kg}}{\mathrm{m}^{2}}$} & $k_{c 1}$ & $k_{c 2}$ & $k_{c 3}$ & $k_{c 4}$ & $k_{c 5}$ \\
\hline & 0.52 & 1.01 & 1.73 & 2.26 & 3.27 \\
\hline & $\omega_{n 1}$ & $\omega_{n 2}$ & $\omega_{n 3}$ & $\omega_{n 4}$ & $\omega_{n 5}$ \\
\hline & 495.95 & 495.60 & 532.85 & 528.49 & 569.11 \\
\hline
\end{tabular}
$(\mathrm{Kg})$ changing for three types of compensations. 
In Table 1, the static stiffness and the resonance frequency of bearing aren't constant, which will be changing with supply pressure or flow rate. And we can get constant flow have the best static stiffness and capillary have the worst. Substituting the experimental result into Eq. (7) can obtain Fig. 7. This figure shows the stiffness of constant flow is better than capillary and membrane-type restrictors in the same load.

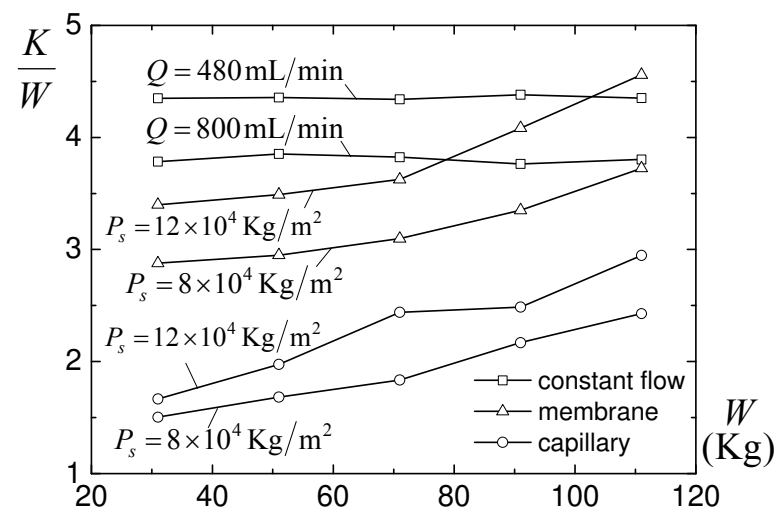

Fig. 7 The various for ratios $K / W$ of film stiffness per load with respect to load $W$

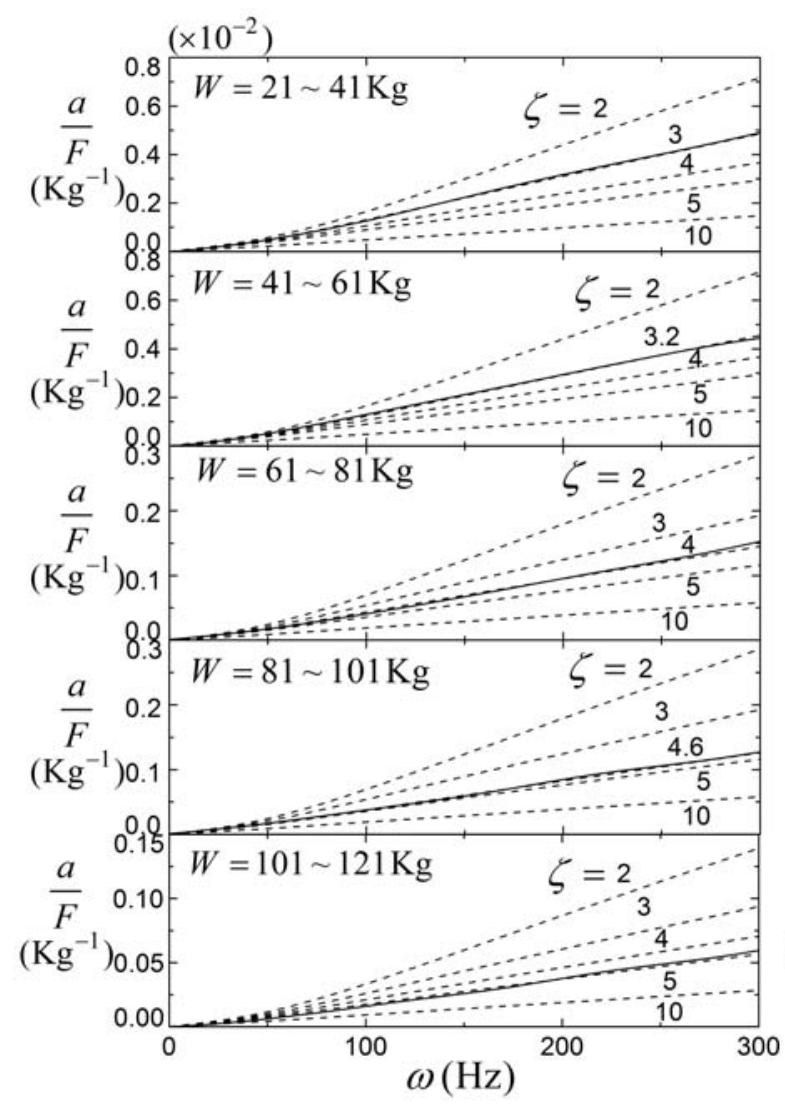

(a) $P_{s}=8 \times 10^{4} \mathrm{Kg} / \mathrm{m}^{2}$

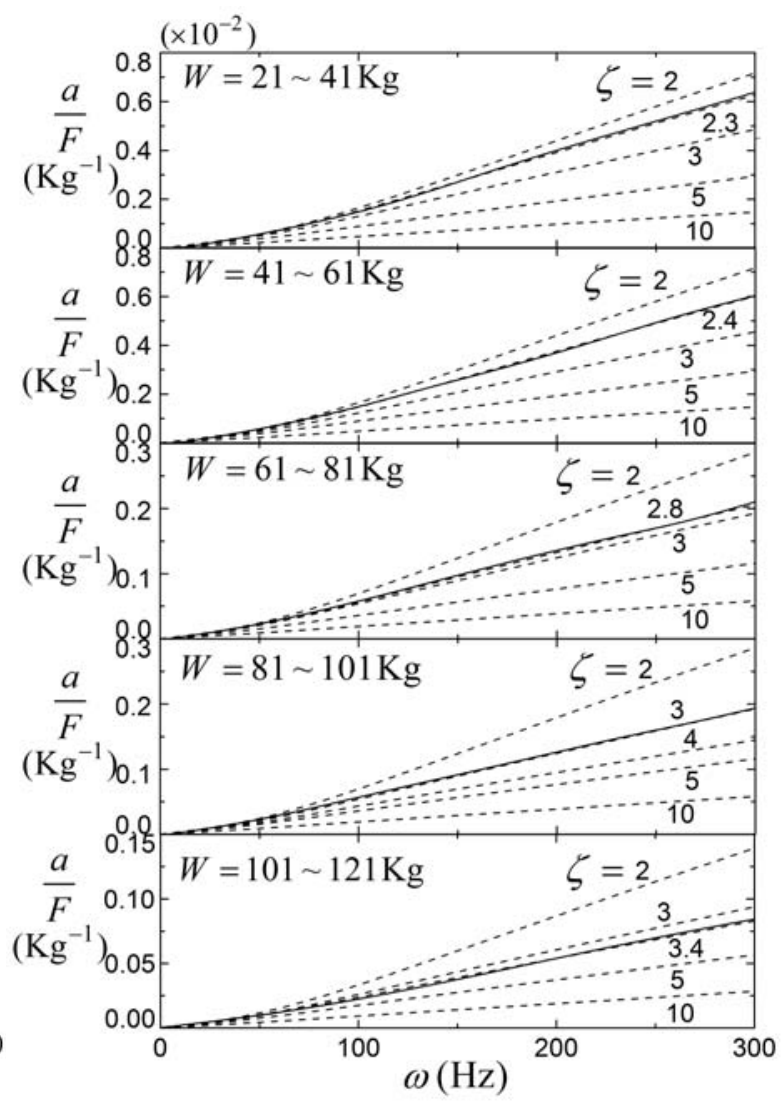

(b) $P_{s}=12 \times 10^{4} \mathrm{Kg} / \mathrm{m}^{2}$

Fig. 8 Acceleration per force $\frac{a}{F}$ versus frequency $\omega$ for capillary restrictor 


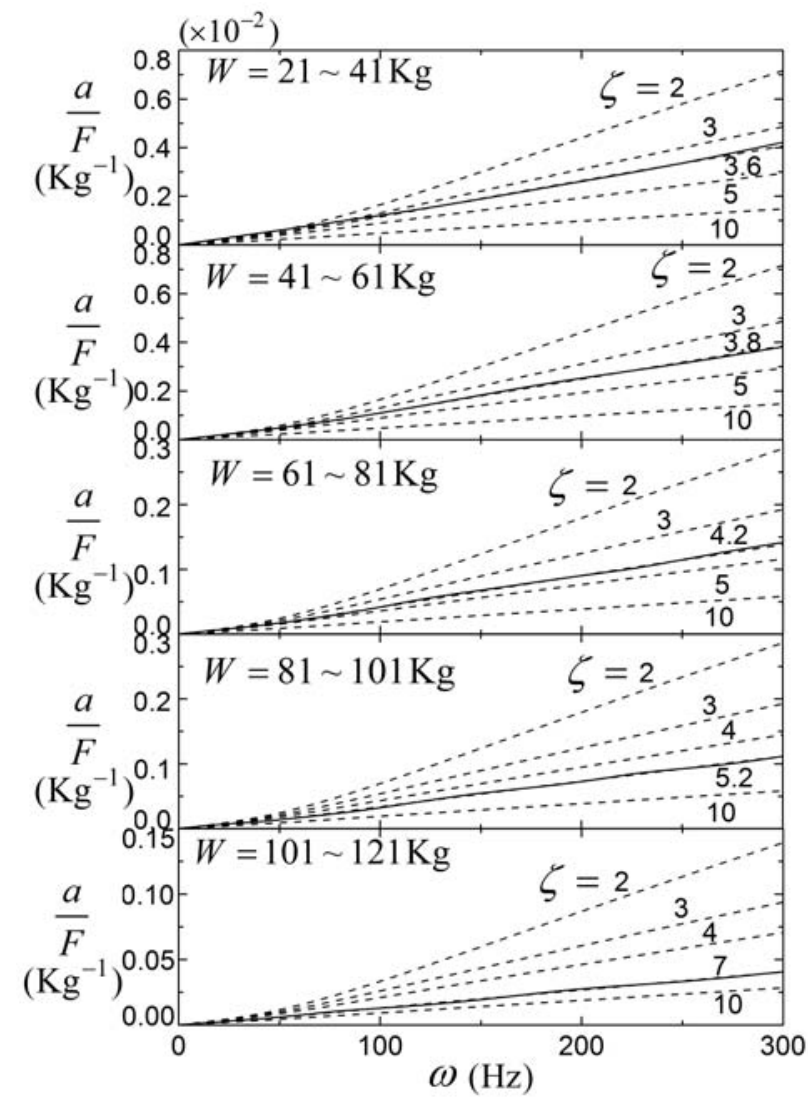

(a) $P_{s}=8 \times 10^{4} \mathrm{Kg} / \mathrm{m}^{2}$

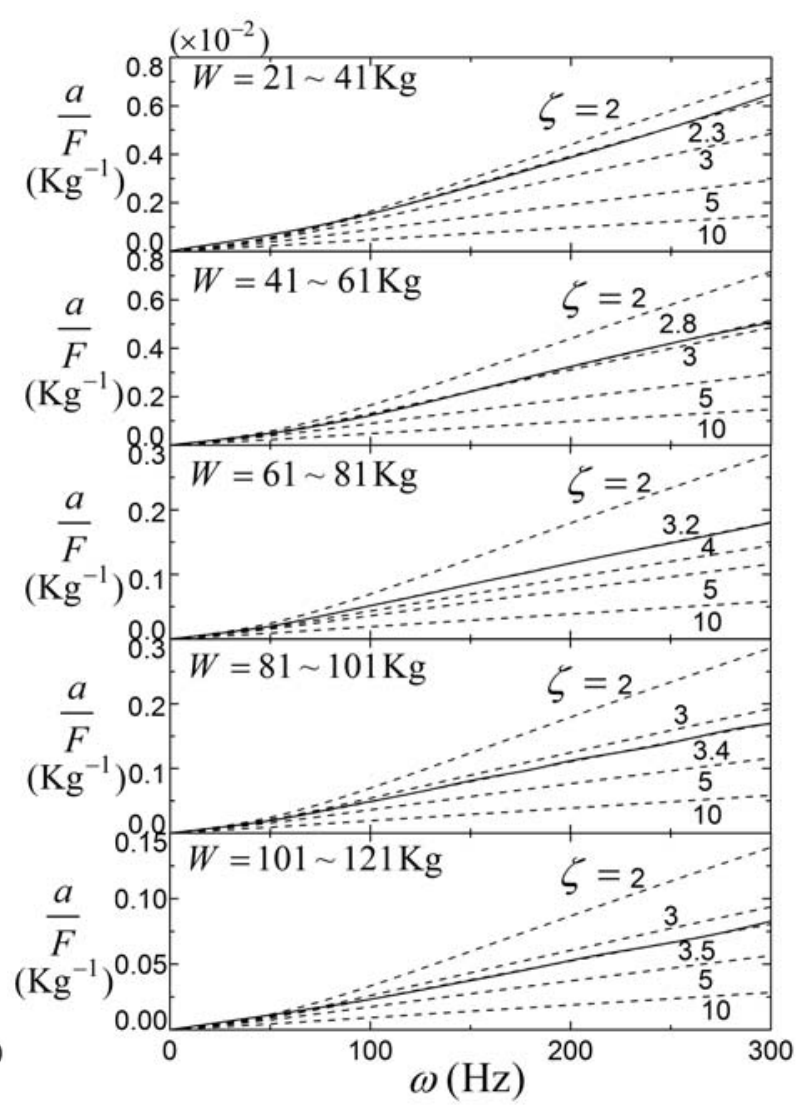

(b) $P_{s}=12 \times 10^{4} \mathrm{Kg} / \mathrm{m}^{2}$

Fig. 9 Acceleration per force $\frac{a}{F}$ versus frequency $\omega$ for membrane restrictor

Figs. 8 to 10 show our evaluation results between experimental results and damping ratio scale for three types of compensations, respectively. The solid line represents experimental data and dashed line means the damping ratio scale of acceleration per force excitation in these figures. We have summarized the evaluation results of the three types of compensations in Table 2. This table shows that the damping ratio increased with an increase in the load ranges. When the load ranges were the same, the damping ratio decreased with an increase in the flow rate. For the capillary restrictor and the membrane-type restrictor, a lower pressure resulted in a larger damping ratio under the same load. A comparison of the three types of compensations under the same load ranges revealed that the constant flow compensation had the largest damping ratio and the capillary restrictor had the smallest damping ratio. Moreover, the increase in load increased the damping ratio. 


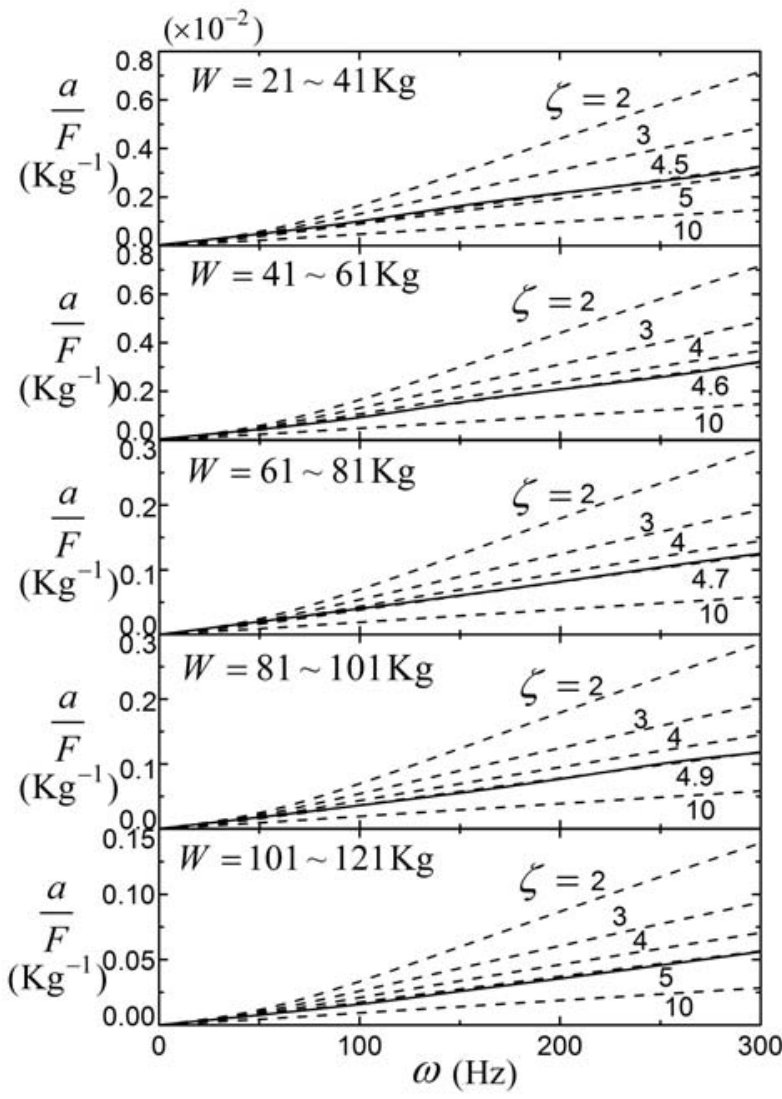

(a) $Q=480 \mathrm{~mL} / \mathrm{min}$

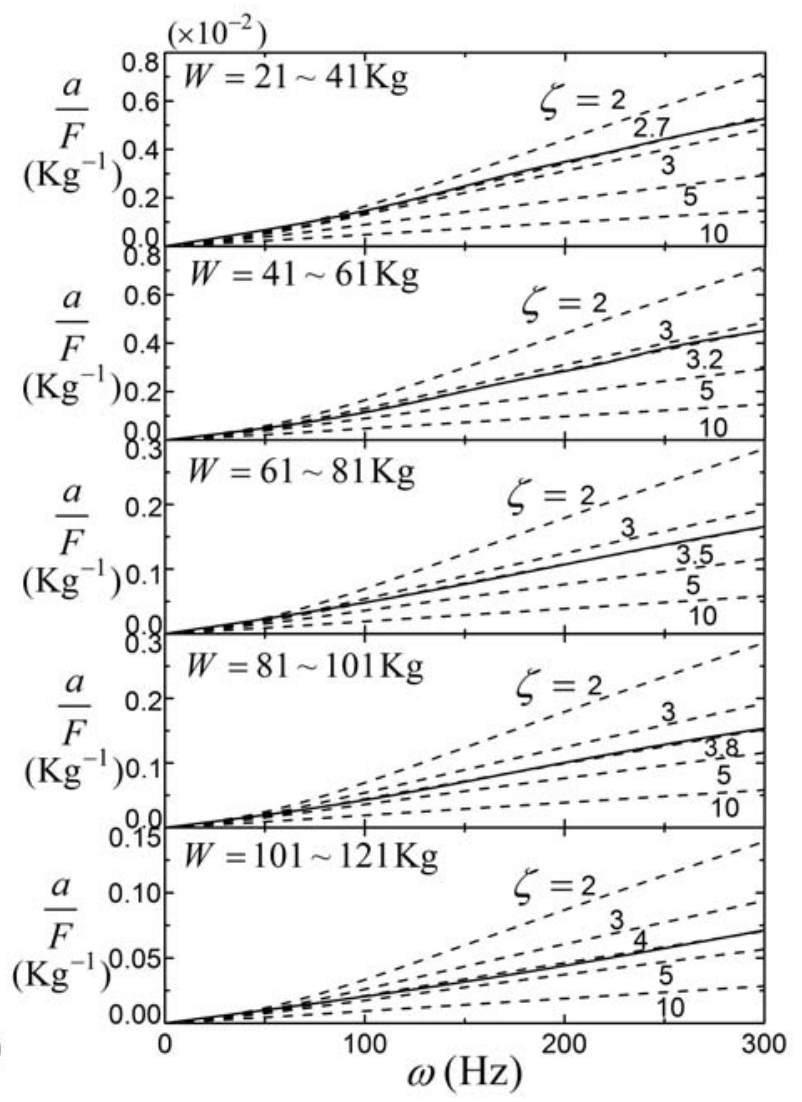

(b) $Q=800 \mathrm{~mL} / \mathrm{min}$

Fig. 10 Acceleration per force $\frac{a}{F}$ versus frequency $\omega$ for constant flow

Table 2 A comparison in damping ratio of hydrostatic bearing with three types of compensations for various load ranges

\begin{tabular}{|c|c|c|c|c|c|c|c|}
\hline \multicolumn{2}{|c|}{ Loading $(\mathrm{Kg})$} & $21-41$ & $41-61$ & $61-81$ & $81-101$ & $101-121$ \\
\hline \multirow{2}{*}{ capillary } & $\begin{array}{c}P_{s} \\
\left(\times 10^{4} \frac{\mathrm{Kg}}{\mathrm{m}^{2}}\right)\end{array}$ & 8 & 3 & 3.2 & 4 & 4.6 & 5 \\
\cline { 3 - 8 } & $\begin{array}{c}P_{s} \\
\text { membrane-type } \\
\left(\times 10^{4} \frac{\mathrm{Kg}}{\mathrm{m}^{2}}\right)\end{array}$ & 8 & 3.6 & 3.8 & 4.2 & 5.2 & 7 \\
\cline { 3 - 8 } constant flow & $\begin{array}{c}Q \\
\left(\frac{\mathrm{mL}}{\mathrm{min}}\right)\end{array}$ & 480 & 4.5 & 4.6 & 4.7 & 4.9 & 5 \\
\cline { 3 - 8 } & 800 & 2.7 & 3.2 & 3.5 & 3.8 & 4 \\
\hline
\end{tabular}




\section{CONCLUSION}

In this paper, a scaling method for damping ratio of hydrostatic film is proposed, which is established by the acceleration frequency response of the SDOF damping ratio evaluation method to obtain the oil film damping ratio of the hydrostatic bearing, which is more direct and easier than other's methods, and experimentally confirmed that this method was applicable in the low-frequency range. We presented a scale method to obtain the damping ratio, covering the whole range of frequencies. The modal test experiments explored constant flow compensation, and two types of pressure compensations are capillary and membrane-type restrictors, respectively. For the constant flow compensation, the damping ratio gets larger as the flow rate being smaller when the same load, and the damping ratio gets larger as the load being larger when the same flow rate. For the capillary and membrane restrictions, the damping ratio gets larger as the supply pressure being smaller when the same load, and the damping ratio gets larger as the load being larger when the same supply pressure. The damping ratio increases as the load is increasing for all of the three types of compensations. In addition, the constant flow compensation has the largest damping ratio, and capillary restriction has the smallest damping ratio for the same load.

\section{Ethical Approval}

My co-author and I hereby declare that the work described was original research that has not been published previously, and is not under consideration for publication elsewhere, in whole or in part.

\section{Consent to Participate}

My co-author and I hereby declare that the manuscript is consenting to participate.

\section{Consent to Publish}

My co-author and I hereby declare that the manuscript is consenting to publish.

\section{Authors Contributions}

Yuan Kang contributed to the conception of the study; Sheng-Yen Hu contributed significantly to analysis and manuscript preparation and wrote the manuscript with Yuan Kang. Wen-Chou Chen and Chien-Hsun Wang performed the experiment; Hsin-Ming Fu helped 
perform the data analyses.

\section{Funding}

My co-author and I hereby declare that No funding citing exists in the study.

\section{Competing Interests}

My co-author and I hereby declare that No conflict of interest exists in the manuscript.

\section{Availability of data and materials}

The data in the manuscript is to verify the feasibility of the damping characteristics scale method provided by us.

\section{ACKNOWLEDGEMENTS}

Sincere thanks to the Ministry of Science and Technology for financial support under the contract of MOST 108-2221-E-033-035- and MOST 108-2221-E-033-037-MY2.

\section{REFERENCES}

[1] Brown GM (1961) The dynamic characteristics of a hydrostatic thrust bearing. Int. J. Mach. Tool D. R. 1: 157-171.

[2] Rohde SM and Ezzat HA (1976) On the Dynamic Behavior of Hybrid Journal Bearings. ASME, J. Lubr. Technol. 98: 90-94.

[3] Ghosh MK and Viswanath NS (1987) Recess Volume Fluid Compressibility Effect on the Dynamic Characteristics of Multirecess Hydrostatic Journal Bearings With Journal Rotation. ASME, J. Tribol. 109: 417-426.

[4] Ghosh MK, Guha SK and Majumdar BC (1989) Rotordynamic coefficients of multirecess hybrid journal bearings part I. Wear 129: 245-259.

[5] Kang Y, Chou HC and Wang YP (2013) Dynamic behaviors of a circular worktable mounting on closed-type hydrostatic thrust bearing compensated by constant compensations. J. Mech. 29: 297-308.

[6] Chang YP, Chen PC, Kang Y, Chen CH and Lee HH (2004) Study in Static and Dynamic Characteristic of Open-type Hydrostatic Slideway. J. Chung Yuan 32: 31-44.

[7] Ewins DJ (1984) Modal Testing: Theory, Practice and Application. Ltd., John Wiley \& Sons, Taunton, UK.

[8] Heylen W, Lammens S and Sas P (1997) Modal Analysis: Theory and Testing. Prentice Hall, Katholieke University Leuven, Belgium. 
[9] De Silva CW (2007) Vibration Damping, Control, and Design. Taylor \& Francis, Boca Raton.

[10] Tiwari R, Lees AW and Friswell MI (2004) Identification of bearing dynamic parameters: A review," Shock Vibr. Dig. 36: 99-124.

[11] Zhang YY, Xie Y and Qiu D (1992) Identification of linearized oil-film coefficients in a flexible rotor-bearing system, part I: Model and simulation. J. Sound Vib. 152: 531-547.

[12] Jolly P, Hassini MA, Arghir M, et al. (2013) Identification of stiffness and damping coefficients of hydrostatic bearing with angled injection. Proc IMechE, Part J: J Eng. Tribol. 227: 905-911.

[13] Mao K, Du Y, Gan S, Li B and Jin L (2018) On the nonlinear dynamic model of open-type constant flow hydrostatic bearings. Lubr. Sci. 30: 1-15.

[14] Rowe WB. (2012) Hydrostatic, Aerostatic and Hybrid Bearing Design. London: Butterworth-Heinemann, 294-301.

[15] Kang Y, Hu SY, Chen WC and Fu HM (2019) Evaluation Damping Performance for Hydrostatic Bearing Film by Damping Ratio Scaling. In: International Conference on Applied Mathematics, Modeling, Simulation and Optimization, Guilin, China, 436-441.

[16] Kang Y, Chen CH, Chen YC, Chang C and Hsiao ST (2012) Parameter identification for single-action membrane-type restrictors of hydrostatic bearings. Ind. Lubr. Tribol. 64: $39-53$. 